\section{Correspondence on 'Efficacy of a tight-control and treat-to-target strategy in axial spondyloarthritis: results of the open-label, pragmatic, cluster-randomised TICOSPA trial'}

We have read with great interest the work of Anna Molto et al studying on comparing the benefits of TICOSPA (a tight control/ treat-to-target strategy (TC/T2T) in axial spondyloarthritis $(\operatorname{axSpA}))$ trial with those of usual care (UC). ${ }^{1}$ They concluded that TC/T2T approach was not significantly superior to UC for the primary outcome, while it might be beneficial in axSpA and had a favourable outcome from a societal health economic perspective. However, we believe that some concerns should be discussed in this important study.

First of all, although the primary endpoint Assessmnet of SpondyloArthritis international Society Healthy Index (ASAS$\mathrm{HI}$ ) was not met due to relatively small sample size and treatment duration, the EQ5D of TC/T2T arm was significantly superior to UC $(p=0.02)$. We understand that ASAS-HI was a newly validated instrument to measure quality of life in ankylosing spondylitis. However, the selection of this tool as primary endpoint in patients with axSpA might not be suitable. On the other hand, EQ-5D is being widely used in a variety of clinical areas, including ankylosing spondylitis in many clinical studies. ${ }^{2-4}$ The difference and sensitivity to detect changes between ASAS-HI and 5-level version of the EuroQol five dimensions (EQ-5D-5L) in axSpA should be also considered in this study.

Second, it is a pity that radiographic evaluation was not available in this study. We suggested that future T2T study in SpA should include Modified Stoke AS Spine Score (mSASSS) which is the most important treatment goal of axSpA by experts' consensus. ${ }^{56}$ We also suggest that the study duration should be extended to at least 2 years to observe the benefit on mSASSS. ${ }^{5}$

Finally, the mean age of study population is 37.9 , but mean disease duration is only 3.7. This is not reasonable because that average age of onset in axSpA should be $20-30 .^{7}$ We wonder that there might be measurement inaccuracy in the disease duration. The relative old age of study subjects might also lead to negative result.

In conclusion, although the primary endpoint was not met, we still see some benefits in the T2T strategy in axSpA in this study. We believe that more T2T studies in SpA should be done before drawing the conclusion. For future T2T studies in SpA, we recommend patient selection of younger age with larger sample size and longer study duration for at least 2 years. ${ }^{5}$

\footnotetext{
Weijie Wang $\odot{ }^{1}$ Yung-Heng Lee, ${ }^{2,3,4}$ James Cheng Chung Wei $\odot^{5,6,7}$

'Department of Rheumatology, The Second Affiliated Hospital of Zhejiang Chinese Medical University, Hangzhou, China

${ }^{2}$ Department of senior services industry management, Minghsin University of Science and Technology, Hsinchu, Taiwan
}

${ }^{3}$ Department of Recreation and Sport Management, Shu-Te University, Kaohsiung, Taiwan

${ }^{4}$ Department of Orthopedics, Cishan Hospital, Ministry of Health and Welfare, Kaohsiung, Taiwan

${ }^{5}$ Institute of Medicine, Chung Shan Medical University, Taichung, Taiwan

${ }^{6}$ Department of Allergy, Immunology \& RheumatologyTaiwan, Chung Shan Medical University Hospital, Taichung, Taiwan

${ }^{7}$ Graduate Institute of Integrated Medicine, China Medical University, Taichung, Taiwan

Correspondence to James Cheng Chung Wei, Institute of Medicine, Chung Shan Medical University, Taichung 404, Taiwan; jccwei@gmail.com

Contributors WW wrote the draft; Y-HL organised the methodology and JCCW supervised the research. All authors contributed to manuscript revision, read and approved the submitted version.

Funding This work was supported by funding from the National Natural Science Foundation of China Grants (82004238).

Competing interests None declared.

Patient and public involvement Patients and/or the public were not involved in the design, or conduct, or reporting or dissemination plans of this research.

Patient consent for publication Not required.

Provenance and peer review Not commissioned; internally peer reviewed.

(C) Author(s) (or their employer(s)) 2021. No commercial re-use. See rights and permissions. Published by BMJ.

\section{Check for updates}

To cite Wang W, Lee Y-H, Wei JCC. Ann Rheum Dis Epub ahead of print: [please include Day Month Year]. doi:10.1136/annrheumdis-2021-220938

Received 7 June 2021

Accepted 8 June 2021

Ann Rheum Dis 2021:0:1. doi:10.1136/annrheumdis-2021-220938

\section{ORCID iDs}

Weijie Wang http://orcid.org/0000-0002-5717-3602

James Cheng Chung Wei http://orcid.org/0000-0003-0310-2769

\section{REFERENCES}

1 Molto A, López-Medina C, Van den Bosch FE, et al. Efficacy of a tight-control and treat-to-target strategy in axial spondyloarthritis: results of the open-label, pragmatic, cluster-randomised TICOSPA trial. Ann Rheum Dis 2021. doi:10.1136/ annrheumdis-2020-219585. [Epub ahead of print: 06 May 2021].

2 Kiltz U, Wei JC-C, van der Heijde D, et al. Ixekizumab improves functioning and health in the treatment of radiographic axial spondyloarthritis: week 52 results from 2 pivotal studies. J Rheumatol 2021;48:188-97.

3 Reveille JD, Hwang MC, Danve A, et al. The effect of intravenous golimumab on healthrelated quality of life and work productivity in adult patients with active ankylosing spondylitis: results of the phase 3 GO-ALIVE trial. Clin Rheumatol 2021;40:1331-41.

4 Sabou S, Mehdian H, Pasku D, et al. Health-related quality of life in patients undergoing cervico-thoracic osteotomies for fixed cervico-thoracic kyphosis in patients with ankylosing spondylitis. Eur Spine J 2018;27:1586-92.

5 Wei JC-C. Treat-to-target in spondyloarthritis: implications for clinical trial designs. Drugs 2014;74:1091-6.

6 Smolen JS, Braun J, Dougados M, et al. Treating spondyloarthritis, including ankylosing spondylitis and psoriatic arthritis, to target: recommendations of an international Task force. Ann Rheum Dis 2014;73:6-16.

7 Burgos-Varga R, Wei JC-C, Rahman MU, et al. The prevalence and clinical characteristics of nonradiographic axial spondyloarthritis among patients with inflammatory back pain in rheumatology practices: a multinational, multicenter study. Arthritis Res Ther 2016;18:132. 